\title{
O QUE É UM ROBÔ? ESTUDO DAS REPRESENTAÇÕES DE CRIANÇAS DE 4-12 ANOS DE IDADE
}

\author{
Cristiane Pelisolli Cabral PPGEDU/UFRGS - pelisolli@gmail.com \\ https://orcid.org/0000-0003-4002-6363 \\ Muriel Lago PPGEDU/UFRGS - muriellago02@gmail.com \\ https://orcid.org/000-0002-5776-0532 \\ Rosane Aragón PPGEDU/PPGIE/UFRGS - rosane.aragon@ufrgs.br \\ https://orcid.org/0000-0002-0307-4457
}

Alexandre da Silva Simões PGEE/UNESP-Sorocaba - alexandre.simoes@unesp.br https://orcid.org/0000-0002-1457-6305

\section{Resumo:}

Neste artigo, apresentaremos um estudo acerca das representações cognitivas de crianças de 4 a 12 anos sobre o que é e como se movimenta um robô. $\mathrm{O}$ objetivo é investigar de que maneira as representações se manifestam em cada período do desenvolvimento cognitivo e sua relação com as experiências físicas, especialmente com as atividades tecnológicas. Os dados coletados foram analisados à luz da Epistemologia Genética de Jean Piaget (1978, 1990, 1999, 2005). Os resultados apontam para uma correlação entre as representações construídas pelas crianças e o desenrolar da construção da representação cognitiva ao longo dos períodos que compõem o desenvolvimento intelectual.

Palavras-chave: Robótica educacional. Desenvolvimento cognitivo. Representação.

\section{WHAT'S A ROBOT? STUDY OF REPRESENTATIONS OF CHILDREN AGED 4-12 YEARS}

\begin{abstract}
:
In this article, we will present a study about the cognitive representations of children aged 4 to 12 years about what a robot is and how it moves. The objective is to investigate how representations are manifested in each period of cognitive development and the relationships with physical experiences, especially with technological activities. The collected data were analyzed in the light of Jean Piaget's (1978, 1990, 1999, 2005) Genetic Epistemology. The results point to a correlation between the representations constructed by the children and the unfolding of the construction of the cognitive representation over the periods that make up intellectual development.
\end{abstract}

Keywords: Educacional robotics. Cognitive development. Representation. 


\section{Introdução}

Atividades tecnológicas envolvendo a robótica e a programação têm alcançado cada vez mais espaço entre as atividades lúdicas das crianças e no meio escolar. Desde os kits semiestruturados de robótica educacional, chamados de Lego Mindstorms, criados por Papert e seu grupo de pesquisa no MIT, na década de 1980, até a robótica livre e os Laboratórios Makers, a aprendizagem envolvendo robôs tem avançado cada vez mais no ambiente infantil.

Ainda que o senso comum parta da premissa de que as crianças da atualidade "nascem sabendo" programação e robótica, a realidade é que nenhum ser humano possui qualquer tipo de conhecimento sobre o mundo ao nascer. Tudo é aprendido e construído através da relação entre o sujeito e o objeto, é o que nos diz a teoria da epistemologia genética do biólogo suíço Jean Piaget (1896-1980). Para ele, a aprendizagem é um processo de adaptação entre o indivíduo e o meio, onde o sujeito assimila tudo aquilo que sua estrutura cognitiva é capaz de assimilar e reorganiza internamente através do mecanismo da acomodação. Através da assimilação e da acomodação, o indivíduo transforma sua estrutura cognitiva, organizando-a em um movimento espiral infinito de integração e reconstrução. Do nascimento até a vida adulta, a estrutura cognitiva do sujeito passará por modificações fundamentais que possibilitarão a abertura para o conhecimento em níveis cada vez mais complexos. Aliás, essa foi justamente a questão que norteou os estudos de Piaget ao longo de toda a sua vida: "Como passamos de um nível menor para outro maior do conhecimento?”. Através dos estudos com crianças recém-nascidas, passando por crianças de mais idade, até as investigações com adolescentes, Piaget observou que a estrutura cognitiva dos sujeitos evolui através de modificações importantíssimas que possibilitam ou não operações intelectuais.

Assim, para Piaget (1978), o desenvolvimento cognitivo do recém-nascido até a fase adulta pode ser dividido em três períodos. O primeiro é o da inteligência sensório-motora que vai do nascimento até o aparecimento da linguagem (por volta dos 2 anos de idade). O segundo período é o da preparação e da organização das operações concretas de classes, relações e número, que se estende dos 2 anos de idade até 11-12 anos, em média, e está subdividido em dois subperíodos, um de preparação funcional das operações e um subperíodo de estruturação propriamente operatória. Um terceiro período, denominado operações formais, inicia-se por volta dos 11-12 anos de idade e atinge o patamar de equilíbrio em torno dos 13-14 anos de idade. Ao longo dos quase 100 livros e 200 artigos publicados, Jean Piaget investigou minuciosamente vários mecanismos envolvidos nos processos cognitivos, entre eles, o da representação. Na obra “A Formação do Símbolo na Criança", Piaget (1990) investiga a questão da representação no desenvolvimento cognitivo infantil do estágio sensório-motor até os primórdios do operatório-concreto. Posteriormente, em uma obra intitulada "A representação do mundo na criança", o epistemólogo buscou investigar "Quais são as representações do mundo criadas espontaneamente pelas crianças ao longo dos diferentes estágios de seu desenvolvimento intelectual" (PIAGET, 2005, p. 9). O objetivo da indagação consiste em perseguir o pensamento da criança a fim de identificar a maneira como a realidade se apresenta para ela.

$\mathrm{O}$ estudo que por hora apresentamos está inserido em uma pesquisa maior que objetiva investigar o processo de construção da noção de algoritmo na atividade de programação realizada por crianças de 4 até 12 anos de idade. A investigação coletou dados através de uma 
entrevista, baseada no método clínico piagetiano, dividida em duas etapas. Na Etapa 1, buscou-se investigar a estrutura cognitiva dos sujeitos através de provas cognitivas e, na Etapa 2, foram realizados experimentos com um robô e a atividade de programação (CABRAL; ARAGÓN; SIMÕES, 2021b). Entre as questões da Etapa 1, foi perguntado para 21 crianças de 4 até 12 anos de idade: "O que é um robô?" e "Como um robô se movimenta?". Os resultados apresentados e discutidos aqui, sob a perspectiva da epistemologia genética, demonstram que eles se relacionam com o desenvolvimento cognitivo infantil e também apontam para a importância do trabalho com a tecnologia para fomentar o desenvolvimento dessas representações.

\section{Desenvolvimento da Cognição e das Representações Infantis}

Pensar nas representações de crianças de 4 a 12 anos acerca do que é um robô e de como ele se movimenta pressupõe adentrar nos aspectos que permeiam o desenvolvimento cognitivo. Portanto, convém retomarmos as características que compõem cada um dos períodos anunciados na introdução e, ao mesmo tempo, delinearmos algumas relações com a evolução da representação cognitiva construída pelos sujeitos neste percurso.

Do nascimento até o aparecimento da linguagem (por volta dos 2 anos de idade), a criança passa pelo período denominado sensório-motor, que é a fase em que inicia seu contato com o mundo através de uma inteligência prática e sensorial, que se desenvolve na direção a uma inteligência senso-motora (marcada pela intencionalidade). Desta forma, a criança assimila todo o universo ao seu corpo, sem dissociar os limites entre eles, para, posteriormente, entender-se como um sujeito entre todos os outros no mundo (PIAGET, 1999).

Nesse percurso, constituído por seis estágios de intensas aprendizagens, o bebê especializa seus reflexos pelo próprio exercício (I), transformando-os, posteriormente em hábitos (reações circulares primárias, relativas ao seu corpo) (II); adiante, as reações circulares serão ampliadas e também aplicadas a objetos manipuláveis (III); em seguida, o bebê passará a coordenar esquemas secundários, utilizando, inicialmente, meios conhecidos para atingir objetivos novos (IV); e, após, diferenciará seus esquemas de ação, buscando novos meios para atingir os fins (V), até interiorizá-los (VI) (PIAGET, 1978).

Portanto, é possível compreender que "a inteligência sensório-motora é, pois, incessantemente, acomodação do esquema antigo ao novo objeto e, ao mesmo tempo, assimilação deste àquele" (PIAGET, 1990, p. 111), visto que o bebê utiliza suas experiências anteriores como suporte para o funcionamento dos mecanismos de assimilação e acomodação. Nesse processo, a assimilação necessita se apoiar em modelos ou cópias estáveis, conferindo à imitação um papel fundamental ao desenvolvimento da inteligência, ao fornecer dados às novas reconstruções (PIAGET, 1990).

Desta forma, no que concerne ao desenvolvimento da representação cognitiva, podemos dizer que o período sensório-motor é marcado por uma diferenciação da imitação em cada um de seus seis estágios acima apresentados. Nos pormenores, inicialmente, o bebê realiza um esforço de repetição de suas ações, o que permite ao reflexo especializar-se em si mesmo (I). Adiante, esta repetição não será mais suficiente, visto que a exploração do bebê ao meio lhe apresentará novidades que exigirão uma atividade acomodativa com vistas a incorporar os elementos novos apresentados. Inicia uma diferenciação progressiva dos esquemas, embora a imitação subsista 
aos modelos conhecidos, seja nas atividades sobre si mesmo, ou nos objetos manipuláveis (II e III). Na sequência, o bebê começa a coordenar os seus esquemas, utilizando-os como meio para outros assimilarem o real. Nesse caso, podemos identificar a inteligência sob o aspecto da coordenação de meios e fins, a partir da utilização de meios conhecidos que são aplicados a novas situações (IV). Posteriormente, essa imitação prolonga-se no sentido de constituir a reprodução de modelos novos. Daqui por diante, a imitação amplia-se cada vez mais, através de uma exploração ativa (V), até o momento em que atinge o seu auge nesta fase, com a imitação diferida (VI), onde o modelo não é mais necessário à imitação. Lembramos que a imitação diferida é a característica que amplia a capacidade da criança conhecer o mundo inserindo-a no período seguinte, onde temos o aparecimento da função simbólica (PIAGET, 1990).

O período de preparação e de organização das operações concretas de classes, relações e número compreende a construção de diferentes noções, todas elas apoiadas em objetos concretos, ou facilmente imagináveis. Por se tratar de um período de intensas transformações, divide-se em dois subperíodos, o primeiro deles, das representações pré-operatórias (2 anos aos 7-8 anos), e o segundo, o das operações concretas (dos 7-8 anos aos 11-12 anos).

No subperíodo das representações operatórias ( 2 anos aos 7-8 anos), presenciamos o aparecimento da função simbólica, das organizações representativas e das regulações representativas articuladas (PIAGET, 1990). É aqui que a criança inicia a distinção entre significante e significado, sendo o primeiro as imagens mentais, e o segundo, o significado que essas imagens constituem. Essa conceituação caracteriza o que Piaget denominou de função simbólica e que permite à criança a representação de fatos/eventos que não estão presentes, mas remontados a partir da interiorização de suas ações. Assim, torna-se capaz de realizar representações por meio de imagem mental, desenhos, por imitação diferida, pelo brinquedo, ou, ainda, pela linguagem (PIAGET, 1990). Buscamos elucidar o exposto a partir das ideias de Piaget (1990, p. 351), ao lembrar que a "representação começa quando os dados sensório-motores atuais são assimilados a elementos simplesmente evocados e não perceptíveis no momento". Tal evocação é possível a partir dos significantes, ou seja, das imagens mentais que o sujeito cria, e que podem ser acionadas na ausência dos objetos reais.

Assim, o pensamento representativo pode ser acionado a partir da imitação e da relação de significantes e significados construída. Nesse caso, podemos entender que a imagem mental precede o gesto, que, por sua vez, constitui-se por um modelo. Além disso, a representação pode ser vislumbrada a partir do jogo simbólico, ou seja, da assimilação de qualquer objeto ao outro através das imagens imitativas. Desta forma, determinados objetos assumem as características de outro, através das imagens mentais que o sujeito evoca. E, por último, o sujeito pode recorrer à representação cognitiva que indica a assimilação dos dados às representações mentais, no sentido de organizar pré-conceitos. Reforçamos a ideia de pré-conceitos, uma vez que os mesmos ainda não podem ser exprimidos em um conjunto ou totalidade mais complexa de relações (PIAGET, 1990).

Outra característica marcante desse subperíodo é a predominância de um pensamento egocêntrico por parte do sujeito, o que o torna incapaz de considerar outros pontos de vista que não sejam os seus, visto que estes, para ele, são os únicos possíveis. Além disso, o pensamento da criança opera sob uma ótica realista, animista e artificialista. Ao ser realista, "a criança 


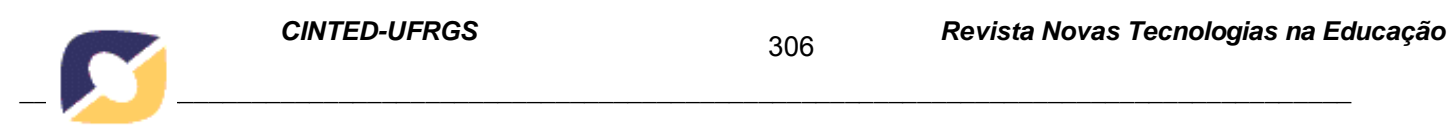

pressupõe que o pensamento está ligado a seu objeto, que os nomes estão ligados às coisas nomeadas [...]. Seu realismo consiste numa tendência espontânea e imediata de confundir o signo com o significado" (PIAGET, 2005, p. 107). O animismo, por sua vez, pode ser compreendido como a tendência da criança "em considerar vivo e consciente um grande número de corpos que, para nós adultos, são inertes” (PIAGET, 2005, p. 143). Por último, o artificialismo consiste em "considerar as coisas como produto da fabricação humana, bem mais do que em atribuir às próprias coisas a atividade fabricadora" (PIAGET, 2005, p. 207). Considerando esses aspectos, torna-se compreensível o posicionamento de Piaget (2005) ao indicar que, inicialmente, toda a representação é entendida pela criança como absoluta, para progressivamente torná-la relativa a determinado ponto de vista.

O subperíodo das operações concretas (dos 7-8 anos aos 11-12 anos) caracteriza-se pela etapa em que importantes estruturas estão em vias de fechamento, constituindo-se uma espécie de semirrede. Nesse momento, presenciamos um aumento da cooperação, uma vez que a criança começa a buscar uma justificação lógica para os fatos. Dessa forma, entendemos que a criança começa a se libertar do egocentrismo social e intelectual a partir de uma crescente descentração (PIAGET, 1999). Como consequência, entram em declínio suas ideias realistas, animistas e artificialistas.

Em relação à atividade representativa, nesse subperíodo, encontramos um crescente equilíbrio entre a assimilação e a acomodação por meio do pensamento intuitivo. A intuição, aqui, pode ser entendida como uma forma superior de equilíbrio que o pensamento atinge nesta fase. Dessa forma, o sistema de relações torna-se mais integrado, devido às operações, através das quais a criança busca coerência nas suas ações. A representação da criança, a partir dos largos progressos na acomodação, é capaz de se reintegrar na inteligência, constituindo um todo que permitirá cada vez mais o seu alargamento. As representações agora são expressas por um conjunto de relações qualificadas e permitem a reversibilidade do pensamento, a partir da consideração de diferentes pontos de vista (PIAGET, 1990).

O terceiro período, o das operações formais, inicia-se por volta dos 11-12 anos e se estende até, aproximadamente, os 13-14 anos, quando o sujeito atinge um patamar de equilíbrio. Logo, as semirredes organizadas no período precedente, por meio das operações, especializam-se, transformando-se em redes, em decorrência da combinatória. Dessa forma, o sujeito é capaz de raciocinar sobre enunciados e hipóteses, desvinculando-se do suporte material ou das representações. O equilíbrio deste período se caracteriza por uma reversibilidade crescente que possibilita ao sujeito pensar a partir de um grupo de transformações, denominado grupo de INRC.

A representação cognitiva, característica desse período, provém da síntese das etapas anteriores, ou seja, da "representação por imagens, simbólica e pré-conceitual, avançando à uma representação de ordem operatória" (PIAGET, 1990, p. 368), para, finalmente atingir sua forma de equilíbrio, a partir de totalidades organizadas, e interrelacionadas entre si, que lhe garantem "mobilidade e reversibilidade completa" (PIAGET, 1990, p. 370). Com base no quadro teórico exposto, passaremos agora para o estudo realizado.

\section{Materiais e Métodos}


O presente estudo está vinculado a uma pesquisa que objetiva investigar o processo de construção da noção de algoritmo na atividade de programação realizada por crianças de 4 até 12 anos de idade. A hipótese inicial é de que exista um percurso cognitivo, quando a criança está programando um computador ou um robô, que faz com que o sujeito consiga transformar a linguagem humana em linguagem de programação. A abordagem escolhida é a qualitativa na perspectiva do estudo de caso (YIN, 2016), com referência nos estudos de Inhelder et al. (1996), buscando analisar o progresso cognitivo macrogenético proposto por Piaget, apoiado em análises detalhadas das condutas dos sujeitos (microgênese), pois elas evidenciam características do processo interativo entre o sujeito e o objeto do conhecimento. Para a investigação dos processos cognitivos envolvidos na atividade de programação com crianças, foi realizada uma entrevista, gravada em vídeo, dividida em duas etapas: na Etapa 1, foram realizadas provas cognitivas baseada no método clínico piagetiano (CARRAHER, 1998; DELVAL, 2002) para a verificação do estágio do desenvolvimento intelectual de cada sujeito; na Etapa 2, os sujeitos resolveram problemas, chamados de experimentos, construindo o algoritmo para fazer movimentar um robô com o material Kids First Coding \& Robotics.

O método clínico piagetiano é um procedimento de coleta e análise de dados para o estudo do pensamento da criança, também aplicável ao estudo do pensamento dos adultos, que se realiza mediante entrevistas ou situações abertas, nas quais se procura acompanhar o percurso do pensamento do sujeito ao longo da entrevista, fazendo sempre novas perguntas para esclarecer respostas anteriores. É composto de algumas perguntas básicas e de outras que variam em função do que o sujeito vai dizendo e dos interesses que orientam a pesquisa que está sendo realizada (DELVAL, 2002). A maioria dos fenômenos psicológicos, tais como o pensamento, a aprendizagem, a memória, o raciocínio, a percepção, entre outros, não são diretamente observáveis pelo pesquisador. Alguns desses fenômenos podem ser constatados pelo próprio sujeito que os vivencia, mas ao cientista é possível apenas a observação de seus indícios. Ainda assim, o raciocínio do sujeito tende a se refletir nas ações e nas escolhas que faz em cada situação. É possível avaliar a motivação de um indivíduo ao resolver um problema, por exemplo, através da sua persistência. Dessa maneira, o estudo de fenômenos psicológicos requer inferências. Inferir a natureza de eventos psicológicos a partir do comportamento observável não é uma questão simples. Os fenômenos psicológicos não existem isolados das suas interações e tornam a interpretação do comportamento uma tarefa desafiadora. O comportamento de alguém ao resolver um problema reflete não apenas seu raciocínio sobre o problema, mas seus objetivos na situação e suas crenças sobre a situação. Logo, um comportamento observado é o resultado de uma interação entre diversos fatores que motivam, situam-se em um contexto, organizam e possibilitam sua execução (CARRAHER, 1998).

A entrevista completa aconteceu em um único encontro, foi gravada em vídeo e analisada com auxílio do software de análise qualitativa MAXQDA2020®. A metodologia, bem como os experimentos propostos, fora aplicada e aperfeiçoada a partir de um estudo piloto realizado anteriormente (CABRAL; ARAGÓN; SIMÕES, 2021a). Para participar do estudo, os sujeitos deveriam ter vínculo escolar e proximidade com uma ou mais tecnologias digitais (celular, tablet, computador, notebook, brinquedos tecnológicos etc.). As entrevistas foram realizadas individualmente. Os pais/responsáveis responderam a um questionário sobre os hábitos da criança com relação ao uso de tecnologias digitais, assinaram o Termo de Consentimento Livre e Esclarecido (TCLE) e as crianças, o Termo de Assentimento Livre e Esclarecido (TALE). A pesquisa está registrada na Comissão Nacional de Ética em Pesquisa (CONEP). Apresentamos 
aqui a análise dos resultados obtidos através de dois questionamentos realizados na Etapa 1 da entrevista, onde foi perguntado para vinte e um (21) sujeitos de 4 até 12 anos de idade as seguintes questões: "O que é um robô?" e "Como um robô se movimenta?".

\section{Resultados e Discussões}

Para a maior parte dos sujeitos investigados de 4-6 anos de idade, um robô se parece com um humanoide, com braços, olhos, cabeça, pernas, barriga e até cabelos. Para outros, é um brinquedo que possui escudo e arma. Além disso, os robôs são vistos em lojas de brinquedos, na televisão e nos pensamentos. As representações de robô das crianças com estrutura cognitiva pré-operatória relacionam-se com objetos que já foram visualizados concretamente por elas em outro momento, seja na loja de brinquedos ou na televisão, isso porque elas encontram-se no subperíodo em que a representação cognitiva está em desenvolvimento e os significantes e significados estão em fase de constituição, através de processos vinculados ao real. Além disso, o egocentrismo característico do período faz com que os sujeitos descrevam o objeto como algo bastante parecido com a figura humana, ou seja, como eles próprios se parecem, até mesmo com cabelos. Conforme o questionário respondido pelos pais/responsáveis juntamente com o TCLE, com exceção de uma criança, nenhuma fez ou faz aulas de tecnologia, tais como robótica ou programação. A síntese dos elementos mencionados encontra-se no Quadro 1:

\begin{tabular}{|l|l|l|l|l|l|l|l|l|l|l|l|l|l|l|l|l|l|l|}
\hline & $\mathbf{1 0}$ & $\mathbf{2}$ & $\mathbf{3}$ & $\mathbf{4}$ & $\mathbf{5}$ & $\mathbf{6}$ & $\mathbf{7}$ & $\mathbf{8}$ & $\mathbf{9}$ & $\mathbf{1 0}$ & $\mathbf{1 1}$ & $\mathbf{1 2}$ & $\mathbf{1 3}$ & $\mathbf{1 4}$ & $\mathbf{1 5}$ & $\mathbf{1 6}$ & $\mathbf{1 7}$ & $\mathbf{1 8}$ \\
\hline S1 & $\mathrm{X}$ & & $\mathrm{X}$ & & & & & & $\mathrm{X}$ & $\mathrm{X}$ & & & & & & & & \\
\hline S2 & & & & & & $\mathrm{X}$ & & & & & & $\mathrm{X}$ & $\mathrm{X}$ & $\mathrm{X}$ & $\mathrm{X}$ & $\mathrm{X}$ & & \\
\hline S3 & & & $\mathrm{X}$ & & $\mathrm{X}$ & $\mathrm{X}$ & $\mathrm{X}$ & & $\mathrm{X}$ & & & & & & & & & \\
\hline S4 & & $\mathrm{X}$ & & $\mathrm{X}$ & $\mathrm{X}$ & $\mathrm{X}$ & & $\mathrm{X}$ & & & & & & & & & & $\mathrm{X}$ \\
\hline S5 & & $\mathrm{X}$ & & $\mathrm{X}$ & $\mathrm{X}$ & & & & & & $\mathrm{X}$ & & & & & & $\mathrm{X}$ & \\
\hline S6 & & $\mathrm{X}$ & & & $\mathrm{X}$ & & & & & & & & & & & $\mathrm{X}$ & & \\
\hline S7 & & & & & & & & & & & & $\mathrm{X}$ & & & & & $\mathrm{X}$ & \\
\hline
\end{tabular}

O que é um robô? (1) um amigo; (2) uma pessoa; (3) tem olhos; (4) tem cabeça; (5) tem braço; (6) tem perna; (7) tem barriga; (8) tem cabelo; (9) é de ferro/lata; (10) é de Lego; (11) é de peças; (12) é um brinquedo; (13) tem escudo; (14) tem arma; (15) voa; (16) vi na televisão; (17) vi na loja; (18) só nos pensamentos.

Com relação à movimentação do robô, para a maioria dos sujeitos de 4-6 anos, um robô se movimenta com pilhas ou baterias, fios e, para isso, é necessário apertar um botão. Mais uma vez, observa-se que os sujeitos com estrutura cognitiva pré-operatória relacionam a movimentação dos robôs com algo conhecido por eles, que são as pilhas/baterias e botões que desencadeiam os movimentos de brinquedos eletrônicos. A síntese dos elementos mencionados na representação dos sujeitos sobre a movimentação dos robôs encontra-se no Quadro 2:

Quadro 2 - Síntese das representações dos sujeitos de 4-6 anos de idade sobre a movimentação dos robôs \begin{tabular}{|l|l|l|l|l|l|}
1 & 2 & 3 & 4 & 5 & 6 \\
\hline
\end{tabular} 


\begin{tabular}{|l|l|l|l|l|l|l|}
\hline S1 & $X$ & & $X$ & & & \\
\hline S2 & $X$ & & & $X$ & & \\
\hline S3 & & & & & & $X$ \\
\hline S4 & $X$ & & $X$ & & $X$ & \\
\hline S5 & & $X$ & & & & \\
\hline S6 & $X$ & & & & & \\
\hline S7 & & $X$ & & & & \\
\hline
\end{tabular}

Como o robô se movimenta? (1) com pilhas/baterias; (2) apertando o botão; (3) com fios; (4) com motores; (5) ligando na tomada; (6) não sabe.

Para os sujeitos de 7-9 anos de idade, que estão em transição do subperíodo pré-operatório para o operatório-concreto, observa-se que há um declínio nas descrições de robôs como humanoides. As crianças maiores, em processo de descentração, utilizam-se de exemplos vistos na televisão ou nas aulas de tecnologia para exemplificar o que é um robô: de luta, de guerra, de entrega, drones, robôs espaciais entre outros. A síntese dos elementos mencionados encontra-se no Quadro 3:

\begin{tabular}{|l|l|l|l|l|l|l|l|l|l|l|l|l|l|l|l|l|}
\hline \multicolumn{10}{c|}{ Quadro 3 - Síntese das representacóes dos sujeitos de 7-9 anos de idade sobre o que } \\
\hline & $\mathbf{1}$ & $\mathbf{2}$ & $\mathbf{3}$ & $\mathbf{4}$ & $\mathbf{5}$ & $\mathbf{6}$ & $\mathbf{7}$ & $\mathbf{8}$ & $\mathbf{9}$ & $\mathbf{1 0}$ & $\mathbf{1 1}$ & $\mathbf{1 2}$ & $\mathbf{1 3}$ & $\mathbf{1 4}$ & $\mathbf{1 5}$ & $\mathbf{1 6}$ \\
\hline S11 & $\mathrm{X}$ & & & $\mathrm{X}$ & & & $\mathrm{X}$ & & & & & & & & & $\mathrm{X}$ \\
\hline S12 & & & & $\mathrm{X}$ & & $\mathrm{X}$ & & $\mathrm{X}$ & & & $\mathrm{X}$ & $\mathrm{X}$ & & & & \\
\hline S13 & & & & & $\mathrm{X}$ & $\mathrm{X}$ & & & & & & & & & & \\
\hline S14 & & & & & & & & & $\mathrm{X}$ & $\mathrm{X}$ & & & $\mathrm{X}$ & $\mathrm{X}$ & & \\
\hline S15 & & & $\mathrm{X}$ & & & & & & & & & & & & & $\mathrm{X}$ \\
\hline S16 & & & & & & & & $\mathrm{X}$ & & & $\mathrm{X}$ & & & & $\mathrm{X}$ & \\
\hline S17 & & $\mathrm{X}$ & & & & & & & & & & & & & & \\
\hline
\end{tabular}

O que é um robô? (1) parecido com pessoa, mas mais inteligente e respeitoso; (2) uma coisa que brinca com a gente; (3) uma coisa criativa; (4) é de metal/aço e fios; (5) é construído; (6) é eletrônico; (7) de luta; (8) de guerra; (9) braço mecânico; (10) entrega coisas; (11) ajuda as pessoas; (12) vai para outros planetas; (13) é um drone; (14) Robô Sofia; (15) tem várias formas; (16) vi na televisão.

Para a maioria dos sujeitos de 7-9 anos, um robô se movimenta através de atuadores, tais como mecanismos, esteiras, rodas etc. Somente dois sujeitos citaram o controlador e três sujeitos citaram a programação como necessários para a movimentação de um robô. Conforme o questionário respondido pelos pais/responsáveis juntamente com o TCLE, somente duas crianças não fazem ou fizeram aula de tecnologia, as demais tiveram ou tem contato com robótica ou 
aulas de programação. A síntese dos elementos mencionados na representação dos sujeitos sobre a movimentação dos robôs encontra-se no Quadro 4:

Quadro 4 - Síntese das representações dos sujeitos de 7-9 anos de idade sobre a movimentação dos robôs

\begin{tabular}{|l|l|l|l|l|l|l|l|l|l|l|}
\hline & 1 & 2 & 3 & 4 & 5 & 6 & 7 & $\mathbf{8}$ & $\mathbf{9}$ & $\mathbf{1 0}$ \\
\hline S11 & $\mathrm{X}$ & $\mathrm{X}$ & & & & & & & & \\
\hline S12 & $\mathrm{X}$ & & $\mathrm{X}$ & $\mathrm{X}$ & $\mathrm{X}$ & $\mathrm{X}$ & & & & $\mathrm{X}$ \\
\hline S13 & & & & & & $\mathrm{X}$ & $\mathrm{X}$ & & & $\mathrm{X}$ \\
\hline S14 & $\mathrm{X}$ & $\mathrm{X}$ & $\mathrm{X}$ & & & & & & & \\
\hline S15 & & & $\mathrm{X}$ & & & & & $\mathrm{X}$ & & \\
\hline S16 & $\mathrm{X}$ & & $\mathrm{X}$ & & & & & & $\mathrm{X}$ & $\mathrm{X}$ \\
\hline S17 & & & & & $\mathrm{X}$ & & $\mathrm{X}$ & & & \\
\hline
\end{tabular}

Como o robô se movimenta? (1) rodas/esteiras; (2) pernas; (3) mecanismos/fios/motor/hélice; (4) metal; (5) alavancas/ botões; (6) tela; (7) controle com USB Bluetooth; (8) pilhas; (9) memória; (10) programação.

Observa-se uma complexidade bem maior nas respostas dadas pelos sujeitos investigados de 10-12 anos de idade. Para estes, um robô é uma máquina inteligente, uma forma da tecnologia, que pode fazer coisas que os seres humanos não podem. A síntese dos elementos mencionados na representação dos sujeitos sobre o que é um robô encontra-se no Quadro 5:

Quadro 5 - Síntese das representações dos sujeitos de 10-12 anos de idade sobre o que é um robô

\begin{tabular}{|l|l|l|l|l|l|l|l|l|l|l|l|l|}
\hline & $\mathbf{1}$ & $\mathbf{2}$ & $\mathbf{3}$ & $\mathbf{4}$ & $\mathbf{5}$ & $\mathbf{6}$ & $\mathbf{7}$ & $\mathbf{8}$ & $\mathbf{9}$ & $\mathbf{1 0}$ & $\mathbf{1 1}$ & $\mathbf{1 2}$ \\
\hline S21 & $\mathrm{X}$ & $\mathrm{X}$ & $\mathrm{X}$ & $\mathrm{X}$ & & & & & & & & \\
\hline S22 & $\mathrm{X}$ & & & & $\mathrm{X}$ & $\mathrm{X}$ & & & & & & \\
\hline S23 & & $\mathrm{X}$ & & & & & $\mathrm{X}$ & $\mathrm{X}$ & & & & \\
\hline S24 & $\mathrm{X}$ & & & & & & & & $\mathrm{X}$ & $\mathrm{X}$ & $\mathrm{X}$ & \\
\hline S25 & $\mathrm{X}$ & & & & & & & & & & & \\
\hline S26 & $\mathrm{X}$ & & & & & & & & & & & \\
\hline S27 & & & & & & & & & & & & $\mathrm{X}$ \\
\hline
\end{tabular}

O que é um robô? (1) máquina inteligente/máquina programada/forma da tecnologia; (2) faz coisas que o ser humano não pode fazer; (3) os seres humanos que desenvolvem os robôs; (4) vai para o espaço; (5) peças; (6) controlador; (7) fazem coisas como humanos; (8) luta sumô; (9) braço robótico; (10) empurram coisas; (11) dançam; (12) peças juntas que formam alguma coisa.

Com relação à maneira como os robôs se movimentam, observa-se que a maior parte dos sujeitos investigados de 10-12 anos de idade citam a programação como algo importante para a movimentação do robô. Conforme o questionário respondido pelos pais/responsáveis juntamente com o TCLE, com exceção de uma criança, todas as demais fizeram ou fazem aulas de tecnologia, tais como robótica ou programação. A síntese dos 
elementos mencionados na representação dos sujeitos sobre a movimentação dos robôs encontra-se no Quadro 6:

Quadro 6 - Síntese das representações dos sujeitos de 10-12 anos de idade sobre a movimentação dos robôs

\begin{tabular}{|l|l|l|l|l|l|}
\hline & $\mathbf{1}$ & $\mathbf{2}$ & $\mathbf{3}$ & $\mathbf{4}$ & $\mathbf{5}$ \\
\hline S21 & $\mathrm{X}$ & $\mathrm{X}$ & & & \\
\hline S22 & $\mathrm{X}$ & & & & \\
\hline S23 & & & $\mathrm{X}$ & $\mathrm{X}$ & \\
\hline S24 & $\mathrm{X}$ & & $\mathrm{X}$ & & \\
\hline S25 & $\mathrm{X}$ & & & & \\
\hline S26 & $\mathrm{X}$ & & & $\mathrm{X}$ & \\
\hline S27 & & $\mathrm{X}$ & & $\mathrm{X}$ & $\mathrm{X}$ \\
\hline
\end{tabular}

Como o robô se movimenta? (1) através da programação; (2) com eletricidade; (3) com pernas e braços; (4) com peças, engrenagens e rodas; (5) precisa de água. 


\section{Conclusão}

Considerando a análise dos dados, podemos identificar que as representações dos sujeitos evoluem de acordo com os períodos do desenvolvimento cognitivo. Assim, é natural que, para as crianças investigadas de 4 a 6 anos, os robôs sejam representados a partir de figuras que se assemelham a humanoides, uma vez que, ao não possuírem experiência prévia com robótica, acabam recorrendo à sua própria experiência com brinquedos e desenhos animados da televisão para exemplificar o seu pensamento. Isso se aplica também ao movimento dos robôs que é explicado a partir da experiência do movimento vivenciado com seus brinquedos eletrônicos. Além disso, a criança não se preocupa em explicar ao pesquisador pormenores que detalhem a sua representação, pois, para ela, o seu ponto de vista é o único possível, e, nesse caso, a explicação detalhada torna-se irrelevante. Retomando os estudos de Piaget (1990), entendemos que todos esses aspectos são direcionados pela perspectiva egocêntrica preponderante nessa faixa etária.

No período seguinte, presenciamos certo declínio do egocentrismo a partir de uma crescente descentração rumo aos períodos seguintes. As representações do conceito de robô se ampliam, surgindo características que indicam a funcionalidade destes (ajuda as pessoas, serve coisas, vai para outros planetas). Identificamos, portanto, que a criança detalha suas representações como se buscasse uma justificativa lógica para a existência dos robôs, pois, se existem, "precisam servir para alguma coisa". Percebe-se que, embora a representação tenha avançado em relação ao grupo anterior, a questão do movimento do robô ainda está atrelada àquilo que é assimilado de maneira concreta, ou a partir de uma representação mais acessível. Por isso, o movimento do robô é atribuído a peças e componentes, ao invés de estar associado ao que de fato provoca a sua movimentação, ou seja, a programação, que nesse caso constitui algo de difícil representação nesse período em que o pensamento se apoia em operações concretas.

Por fim, com o declínio do egocentrismo e, por conseguinte, um aumento da descentração, as crianças demonstram um avanço em suas representações, guiadas por sua capacidade de reversibilidade do pensamento. Portanto, vislumbramos uma descrição cada vez mais qualificada, que mostra uma ampliação de possibilidades, como se aquilo que foi apresentado como resposta constituísse apenas uma parcela de um todo possível. Isso ocorre porque as crianças não operam mais a partir de pontos de vistas individuais, mas são capazes de coordenar os diferentes pontos de vista. Em relação ao movimento dos robôs, percebemos uma crescente associação a elementos que não são "visíveis", como, por exemplo, programação e eletricidade. Cabe mencionar que essa perspectiva de conexão entre o movimento e suas formas de produção abstratas não foi relatado pelos sujeitos dos períodos anteriores. Além disso, a experiência com aulas de tecnologia, como robótica e programação acrescentaram, no caso dos sujeitos de 7-9 anos e de 10-12 anos, elementos às representações que não estariam presentes se não em função do trabalho realizado anteriormente com esses sujeitos.

Nesse sentido, entende-se que os resultados aqui apresentados podem contribuir para a reflexão de professores e demais envolvidos com metodologias e práticas de robótica educacional, uma vez que nos mostram que as experiências anteriores dos sujeitos em aulas de robótica educacional ampliam os seus conhecimentos e representações, contribuindo para o seu desenvolvimento cognitivo. Conclui-se que as experiências desencadeadas em oficinas e demais atividades tecnológicas aperfeiçoam o repertório dos sujeitos e, gradativamente ao desenvolvimento intelectual, tornam-se suporte para a construção de um pensamento formal, no qual a representação e o conhecimento ultrapassam as dimensões do real, construindo uma rede de possibilidades que se torna alicerce para as aquisições futuras. 


\section{Agradecimentos}

O presente trabalho foi realizado com apoio da Coordenação de Aperfeiçoamento de Pessoal de Nível Superior - Brasil (CAPES) - Código de Financiamento 001.

\section{Referências}

CABRAL, C. P.; ARAGÓN, R.; SIMÕES, A. S. Atividade de programação com crianças de 4-6 anos: a construção da noção de algoritmo. Renote, v. 19, n. 1, p. 413-422, 2021 a.

CABRAL, C. P.; ARAGÓN, R.; SIMÕES, A. S. Desenvolvimento cognitivo e a atividade de programação com crianças. Revista Pesquisa Qualitativa, v. 9, n. 20, p. 114-142, 2021b.

CARRAHER, T. N. O Método Clínico: usando os exames de Piaget. 5. ed. São Paulo: Cortez, 1998.

DELVAL, J. Introdução à Prática do Método Clínico: descobrindo o pensamento das crianças. Porto Alegre: Artmed, 2002.

INHELDER, B. et al. $\mathbf{O}$ desenrolar das descobertas na criança: pesquisa acerca das microgêneses cognitivas. Porto Alegre: Artes Médicas, 1996.

PIAGET, J. A representação do mundo na criança. 5. ed. São Paulo: Ideias \& Letras, 2005. PIAGET, J. Seis estudos de psicologia. Rio de Janeiro: Forense Universitária, 1999. PIAGET, J. Problemas de Psicologia Genética. São Paulo: Abril Cultural, 1978. PIAGET, J. A formação do símbolo na criança: imitação, jogo e sonho, imagem e representação. Rio de Janeiro: LTC, 1990.

YIN, R. Pesquisa Qualitativa do Início ao fim. Porto Alegre: Penso, 2016. 